\title{
Analysis of the Effect of Proton-Pump Inhibitors on the Course of COVID-19
}

This article was published in the following Dove Press journal:

Journal of Inflammation Research

\author{
Xiao-Yu Zhang $\mathbb{D}^{1, *}$ \\ Tao $\mathrm{Li}^{2} *$ \\ Haibing $\mathrm{Wu}^{3}$ \\ Yun Ling ${ }^{4}$ \\ Zhi-Ping Qian ${ }^{5}$ \\ Liang Chen'
}

'Department of Liver Disease, Shanghai Public Health Clinical Center, Fudan University, Shanghai, 201508, People's Republic of China; ${ }^{2}$ Department of Tuberculosis Disease, Shanghai Public Health Clinical Center, Fudan University, Shanghai, 201508, People's Republic of China; ${ }^{3}$ Department of Neurosurgery, Shanghai Public Health Clinical Center, Fudan University, Shanghai, 201508, People's Republic of China; ${ }^{4}$ Department of Infectious Disease, Shanghai Public Health Clinical Center, Fudan University, Shanghai, 201508, People's Republic of China; ${ }^{5}$ Department of Severe Hepatopathy, Shanghai Public Health Clinical Center, Fudan University, Shanghai, 201508, People's Republic of China

*These authors contributed equally to this work
Correspondence: Liang Chen; Xiao-Yu Zhang

Department of Liver Disease, Shanghai Public Health Clinical Center, Fudan University, Shanghai, 20I508, People's Republic of China

Tel +86I89308I0000; +86I305225I333

Email chenliang65@yeah.net;

zhangxiaoyuPRC@I63.com
Objective: This study is to evaluate the effect of proton-pump inhibitors on the course of COVID-19.

Methods: Clinical data of moderate COVID-19 patients admitted to the Shanghai Public Health Clinical Center for treatment from January 20, 2020, to March 16, 2020, were collected. A retrospective study was conducted and the patients were divided into two groups according to whether they used proton-pump inhibitors or not. The differences in SARS-CoV -2 clearance and hospital stay between the two groups were compared by Cox proportional hazards $(\mathrm{PH})$ regression models and the propensity score matching method.

Results: A total of 154 patients with moderate COVID-19 were included in this study, including 80 males $(51.9 \%)$, 35 patients $(22.7 \%)$ in the proton-pump inhibitor group, and 119 patients $(77.3 \%)$ in the control group. In the proton-pump inhibitor group and the control group, the duration of the SARS-CoV-2 clearance was 7 days (95\% CI, 6-9) and 7 days (95\% CI, 6-11), and the duration of the hospital stay was 21 days (95\% CI, 16-25) and 20 days (95\% CI, 15-26), respectively. There was no significant difference between the both groups in the cumulative incidence of the SARS-CoV-2 clearance and the discharge, and the same results were obtained after the propensity score matching, all $\mathrm{P}>0.05$. There was no significant association between the use of proton-pump inhibitors and the duration of SARSCoV-2 clearance, according to univariate analysis (HR, 1.309; 95\% CI, 0.893-1.918) and multivariate analysis (HR, 1.575; 95\% CI, 0.993-2.499). There was no significant association between the use of proton-pump inhibitors and the duration of hospital stay for COVID19, according to univariate analysis (HR, 1.044; 95\% CI, 0.714-1.528) and multivariate analysis (HR, 1.064; 95\% CI, 0.651-1.740).

Conclusion: The use of proton-pump inhibitors has no effect on prolonging or shortening the course of adults hospitalized with COVID-19.

Keywords: COVID-19, SARS-CoV-2, proton-pump inhibitors, SARS-CoV-2 clearance, hospital stay

\section{Introduction}

The disease burdens of coronavirus disease 2019 (COVID-19), caused by severe acute respiratory syndrome coronavirus-2 (SARS-CoV-2), have been continuously increasing. ${ }^{1}$ Globally, as of 5:22 pm CET, December 19, 2020, there have been 74,299,042 confirmed cases of COVID-19, including 1,669,982 deaths, reported to WHO. ${ }^{2}$ Some COVID-19 patients have obvious gastrointestinal symptoms, ${ }^{3,4}$ and some basic diseases and therapeutic drugs may cause damage to the gastric mucosa; which can lead to proton-pump inhibitors (PPIs) being used to various degrees in the treatment of COVID-19. 
However, PPIs have been found in several clinical studies to increase the incidence of community-acquired pneumonia or hospital-acquired pneumonia. ${ }^{5-12}$ On the other hand, studies have shown that PPIs did not increase the incidence of pneumonia. They believed that the increased incidence of pneumonia caused by PPIs was due to confounding factors, and PPIs themself were not an independent factor affecting the occurrence of pneumonia. ${ }^{13-16}$ In addition, studies have shown that PPIs could effectively inhibit virus and can be tried to treat viral infection and respiratory disease. ${ }^{17,18}$

It is not clear whether PPIs could have a significant impact on COVID-19. The purpose of this study is to analyze whether the use of PPIs has relation with the duration of SARS-CoV-2 clearance and hospital stay for the patients with COVID-19.

\section{Methods Study Design}

A retrospective cohort study design was conducted in the Shanghai Public Health Clinical Center affiliated to Fudan University, a designated tertiary teaching hospital for the treatment of SARS-CoV-2 infection. Patients with moderate COVID-19 confirmed diagnosis during the first 3 days in the hospital from January 20, 2020, to March 16, 2020, were included, and those cases would be followed up to discharge. The informed consents of patients were collected, including their data being used for research, and that this study was conducted in accordance with the Declaration of Helsinki.

\section{Patients and Definitions}

A total of 298 adults were diagnosed with moderate COVID-19 in the first 3 days after admission.

Moderate COVID-19 criteria were as follows: 1) the patients had epidemiological contact history or clinical manifestations; 2) pneumonia could be seen on imaging; 3) the examination of SARS-CoV-2 RNA was positive by reverse transcription polymerase chain reaction (RT-PCR); 4) respiratory rate $>12$ times $/ \mathrm{min}$ and $<30$ times $/ \mathrm{min}$, oxygenation index $>300 \mathrm{mmHg}$, oxygen concentration $>93 \%$ in resting state; 5) no shock and organ failure.

SARS-CoV-2 clearance criteria: the examination of SARS-CoV-2 RNA was negative for two consecutive pharyngeal swabs, and sampling time interval was at least 24 hours.

Discharge criteria were as follows: 1) body temperature returned to normal for more than 3 days; 2) respiratory symptoms improved significantly; 3) pulmonary $\mathrm{CT}$ scan showed basic absorption of acute exudative lesions; 4) the patients obtained SARS-CoV-2 clearance.

\section{Inclusion and Exclusion Criteria}

A total of 154 cases were enrolled in the analysis. Of which the 144 cases were excluded, 27 cases were given PPIs for less than 3 days before the SARS-CoV- 2 clearance, 12 cases had no nucleic acid test within the first 3 days after admission, 104 cases lacked continuous detection data required for the study design, and 1 case died who was not exposed to PPIs. The detailed cases are shown in Figure 1.

Cases inclusion criteria were as follows: 1) cases were diagnosed with moderate COVID-19 within first 3 days after admission; 2) cases were men or women higher than 18; 3) the examination of SARS-CoV-2 RNA was positive for the cases during the first 3 days after hospitalization; 4) the examination of SARS-CoV-2 RNA was continuous; 5) cases in the PPI group were treated with PPIs for more than 3 days before the SARS-CoV-2 clearance, while cases in the control group had not received drugs to suppress gastric acid secretion; 6 ) the daily dose of omeprazole was $20 \mathrm{mg}$ or $40 \mathrm{mg}$, or the daily dose of rabeprazole was $20 \mathrm{mg}$.

Cases exclusion criteria were as follows: 1) the cases used drugs to inhibit the secretion of gastric acid within 30 days before admission; 2) the SARS-CoV-2 RNA of cases was detected at intervals of more than 48 hours; 3 ) cases in the PPI group were treated with PPIs for less than 3 days before the SARS-CoV-2 clearance; 4) the cases data were incomplete; 5) the cases died in the course of hospitalization.

\section{Cases Grouping and Requirements}

PPI group: the cases were exposed to PPIs and met the above inclusion and exclusion criteria. A total of 35 eligible cases were included in the PPI group.

Control group: the cases were not exposed to drugs that suppressed the secretion of gastric acid and met the above inclusion and exclusion criteria. A total of 119 eligible cases were included in the control group.

\section{Data Sources and Indicators}

The demographic and clinical data were collected from electronic medical record (EMR) including hospital information system (HIS), laboratory information system (LIS) and radiology information system (RIS) of the Shanghai Public Health Clinical Center. The demographic 


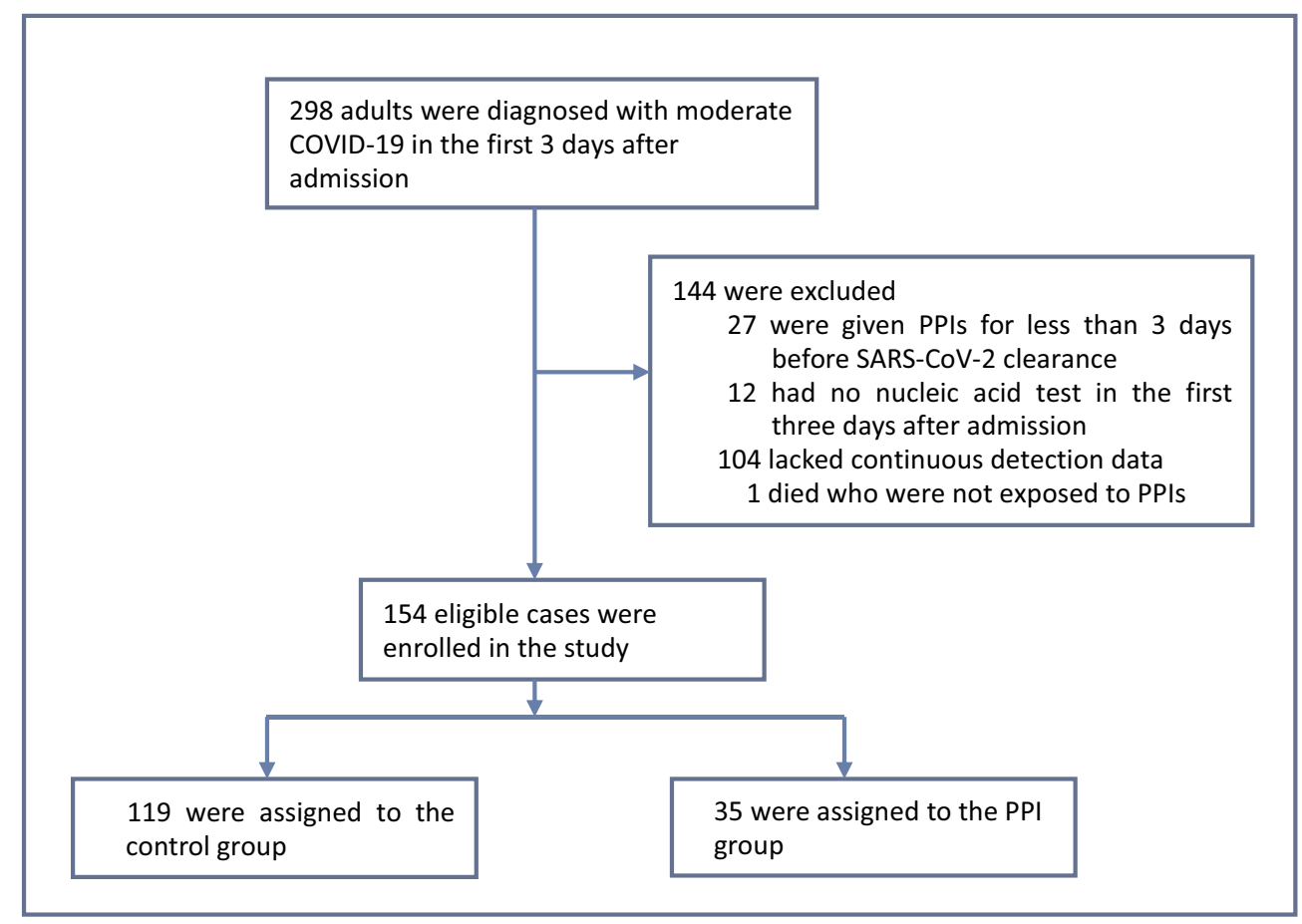

Figure I Study cohort.

and clinical data included age and sex of the patients, the number of pulmonary lobe inflammation by COVID-19 on the CT scan, the onset times, the duration of the SARS$\mathrm{CoV}-2$ clearance after hospitalization, the duration of hospital stay, history of hypertension (HPT), diabetes mellitus (DM), cardiovascular disease (CVD), chronic obstructive pulmonary disease (COPD), chronic liver disease (CLD), chronic gastric disease (CGD), chronic kidney disease (CDK), malignant tumor (MT), alanine aminotransferase (ALT), aspartate aminotransferase (AST), creatine kinase (CK), lactate dehydrogenase (LDH), albumin (ALB), prealbumin (PA), creatinine (Cr), D-dimer (D-D), leukocyte (WBC), neutrophils (Neu), lymphocyte (Lym), blood platelet (PLT), and CD4positive T-lymphocytes (CD4, CD4 cells). All the baseline information was collected within 24 hours after admission.

The test specimens of the SARS-CoV-2 RNA in this study were nasopharyngeal swabs, detected by the Shanghai Municipal Center for Disease Control and Prevention before admission, while sampled and detected in the Shanghai Public Health Clinical Center after admission. All the cases which were admitted to the Shanghai Public Health Clinical Center were tested positive for SARS-CoV-2 RNA in the Shanghai Municipal Center for Disease Control and Prevention before hospitalization.

\section{Statistical Analyses}

The data were described as median (interquartile range) or numbers (\%). Pearson chi-square test and fisher exact probability method were used for the counting data. The normality of continuous variables was tested by $\mathrm{K}-\mathrm{S}$ test. $t$-Test was used for the differences between data groups conforming to normal distribution, while Manny-Whitney $U$-test was used for the differences between data groups not conforming to normal distribution.

The cumulative probability of the SARS-CoV-2 clearance or the discharge was conducted through KaplanMeier statistics, and the difference was examined by Log Rank test. The possible risk factors of the SARS-CoV-2 clearance or the discharge were investigated with Cox proportional hazards $(\mathrm{PH})$ regression models for univariate and multivariate analyses to estimate hazard ratios (HRs) and $95 \%$ confidence intervals (CIs). $\mathrm{PH}$ assumption was verified using Schoenfeld residuals.

In order to control the influence of selectivity bias and confounding factors, the propensity score matching method was adopted by logistic regression based on the demographic and clinical indicators in this study. The difference between the two groups was balanced by 1:1 propensity score matching (PS-matching).

SPSS software version 23.0 (SPSS Inc. Chicago, IL, USA) was used for statistical analysis of the data. 
A P value of two-sided less than 0.05 was considered as statistically significant.

\section{Results}

\section{Baseline Status of COVID-19 Cases}

A total of 154 COVID-19 cases were included in this study, including 80 males $(51.9 \%), 35$ cases $(22.7 \%)$ in the PPI group, and 119 cases (77.3\%) in the control group. There was no significant difference between the PPI group and the control group in age, sex, hypertension, diabetes mellitus, cardiovascular disease, chronic obstructive pulmonary disease, chronic liver disease, chronic gastric disease, chronic kidney disease, malignant tumor, the number of pulmonary lobe inflammation on the CT scan, the onset times, duration of the SARS-CoV-2 clearance, hospital stays, alanine aminotransferase, aspartate aminotransferase, creatine kinase, lactate dehydrogenase, albumin, prealbumin, creatinine, D-dimer, leukocyte, neutrophils, lymphocytes, platelet and CD4 cells; all $\mathrm{P}>0.05$. Baseline characteristics of cases are shown in Table 1.

\section{Comparison of Virus Clearance and Hospital Stay}

The duration of the SARS-CoV-2 clearance in the PPI group and the control group were 7(6-9) and 7(6-11) days, respectively. There was no significant difference in the cumulative incidence of the SARS-CoV-2 clearance between the both groups, $\mathrm{P}=0.123$. The duration of hospital stay for COVID-19 cases was $21(16-25)$ days in the PPI group and 20 (15-26) days in the control group. There was no significant difference between the both groups in the cumulative incidence of the discharge for COVID-19 cases, $\mathrm{P}=0.812$. The detailed information is shown in Table 1 and Figure 2.

\section{Analysis of the Factors Influencing Viral Clearance and Hospital Stay Analysis of Factors Affecting the SARS-CoV-2 Clearance of COVID-19 Patients}

Univariate analysis showed that chronic gastropathy prolonged the duration of the SARS-CoV-2 clearance in COVID-19 cases, HR 15.202 (3.331-69.377), $\mathrm{P}<0.001$. Multivariate analysis showed that chronic gastropathy prolonged the duration of SARS-CoV-2 clearance in COVID19 cases, HR was 20.924 (3.547-123.447), $\mathrm{P}<0.001$. There was no significant difference in the remainder, and all $\mathrm{P}>0.05$. The detailed Cox regression results are shown in Table 2.

Analysis of Factors Affecting the Duration of Hospital Stay for COVID-19 Patients

Univariate analysis: chronic liver disease and chronic gastric disease prolonged the duration of hospital stay in COVID-19 cases, HR were $6.183(2.18-17.534)$ and 4.155 (1.011-17.078), respectively, both $\mathrm{P}<0.05$. The SARS-CoV-2 clearance shortened the duration of hospital stay in COVID-19 cases, HR was 0.911 (0.876-0.948), $\mathrm{P}<0.05$. Multivariate analysis: hypertension, chronic obstructive pulmonary disease, chronic liver disease, and malignant tumor prolonged the duration of hospital stay in COVID-19 cases, HR were 1.820 (1.073-3.085), 4.370 (1.205-15.844), $9.011 \quad(2.681-30.290), 5.270$ (1.237-22.456), respectively, all $\mathrm{P}<0.05$. The SARS-CoV-2 clearance shortened the duration of hospital stay in COVID-19 cases, HR was 0.907 (0.869-0.947), P < 0.05 . There was no significant difference in the remainder, and all $\mathrm{P}>0.05$. The detailed Cox regression results are shown in Table 3.

\section{PS-Matching Analysis of Virus Clearance and Hospital Stay}

A total of 29 pairs of cases were collected by 1:1 propensity score matching, and the corresponding data are shown in Table 4. The duration of SARS-CoV-2 clearance in the PPI group and the control group was 8(6-9) and 8(7-11) days, respectively. There was no significant difference in the cumulative incidence of SARS-CoV-2 clearance between the both groups, $\mathrm{P}=0.355$. The duration of hospital stay for COVID-19 cases was 21 (16-27) days in the PPI group and 19 (16-24) days in the control group. There was no significant difference between the both groups in the cumulative incidence of discharge for COVID-19 cases, $\mathrm{P}=0.817$. Table 4 and Figure 3 show the detailed information.

\section{Discussion}

Some patients need to be treated with PPIs, such as gastric acid-related diseases, anticoagulants or drugs that may cause obvious adverse reactions in the gastrointestinal tract. However, studies reporting the risk of pneumonia from PPIs use have been inconsistent. Especially in this COVID-19 outbreak, it is difficult to draw on appropriate references regarding the safety or risk of PPIs in COVID19 cases, which is also controversial at present. Currently, 
Table I Baseline Data Among the Enrolled Cases of COVID-19

\begin{tabular}{|c|c|c|c|}
\hline & $\begin{array}{l}\text { PPI Group } \\
(n=35)\end{array}$ & $\begin{array}{l}\text { Control Group } \\
(n=119)\end{array}$ & $\mathbf{P}$ \\
\hline Age (years) & $50(35-65)$ & $52(36-64)$ & 0.947 \\
\hline Sex,male (\%) & $\mid 8(5 \mid .4)$ & $62(52.1)$ & 0.944 \\
\hline HPT (\%) & $7(20)$ & $28(23.5)$ & 0.661 \\
\hline DM (\%) & $2(5.7)$ & $10(8.4)$ & 0.870 \\
\hline CVR (\%) & $2(5.7)$ & $5(4.2)$ & 1.000 \\
\hline COPD (\%) & $I(2.9)$ & $2(1.7)$ & $0.54 \mathrm{I}$ \\
\hline CLD (\%) & $\mathrm{I}(2.9)$ & $3(2.5)$ & 1.000 \\
\hline CGD (\%) & $0(0)$ & $2(1.7)$ & 1.000 \\
\hline CKD (\%) & $2(5.7)$ & $0(0)$ & 0.051 \\
\hline MT (\%) & $0(0)$ & $3(2.5)$ & 1.000 \\
\hline NPLI & $3(2-5)$ & $4(2-5)$ & 0.660 \\
\hline $\begin{array}{l}\text { The onset times } \\
\text { (days) }\end{array}$ & $3(2-6)$ & $4(2-7)$ & 0.418 \\
\hline $\begin{array}{l}\text { SARS-CoV-2 } \\
\text { clearance (days) }\end{array}$ & $7(6-9)$ & $7(6-11)$ & 0.691 \\
\hline Hospital stays (days) & $21(16-25)$ & $20(15-26)$ & 0.507 \\
\hline ALT (U/L) & $21(15-30)$ & $22(16-35)$ & 0.643 \\
\hline AST (U/L) & $26(20-42)$ & $25(20-33)$ & 0.533 \\
\hline CK (U/L) & $102(55-194)$ & $80(55-127)$ & 0.190 \\
\hline LDH (U/L) & $231(193-305)$ & $219(190-293)$ & 0.745 \\
\hline ALB $(g / L)$ & $\begin{array}{l}41.0 \\
(37.9-44.0)\end{array}$ & $4 I .2(38.1-44.1)$ & 0.528 \\
\hline PA (mg/L) & $151(93-193)$ & $158(104-207)$ & 0.355 \\
\hline $\mathrm{Cr}(\mu \mathrm{mol} / \mathrm{L})$ & $\begin{array}{l}70.5 \\
(52.4-77.3)\end{array}$ & $61.3(50.5-77.1)$ & 0.328 \\
\hline D-D (mg/L) & $\begin{array}{l}0.36 \\
(0.28-0.50)\end{array}$ & $0.37(0.26-0.64)$ & 0.828 \\
\hline WBC $\left(\times 10^{9} / \mathrm{L}\right)$ & $4.4(3.7-5.7)$ & $4.9(4.0-5.9)$ & 0.227 \\
\hline Neu (\%) & $\begin{array}{l}65.4 \\
(55.2-70.6)\end{array}$ & $66.6(58.2-72.6)$ & 0.255 \\
\hline $\operatorname{Lym}\left(\times 10^{9} / \mathrm{L}\right)$ & $\begin{array}{l}1.04 \\
(0.73-1.38)\end{array}$ & $1.13(0.79-1.52)$ & 0.196 \\
\hline PLT $\left(\times 10^{9} / \mathrm{L}\right)$ & $163(|2|-20 \mid)$ & $176(143-2 \mid 8)$ & 0.218 \\
\hline CD4 (cell/ $/ \mu \mathrm{l})$ & $4 I I(264-7 \mid 7)$ & $456(302-650)$ & 0.711 \\
\hline
\end{tabular}

Abbreviations: PPIs, proton-pump inhibitors; HPT, hypertension; DM, diabetes mellitus; CVD, cardiovascular disease; COPD, chronic obstructive pulmonary disease; CLD, chronic liver disease; CGD, chronic gastric disease; CKD, chronic kidney disease; MT, malignant tumor; NPLI, number of pulmonary lobe inflammation; ALT, alanine aminotransferase; AST, aspartate aminotransferase; $C K$, creatine kinase; $\mathrm{LDH}$, lactate dehydrogenase; ALB, albumin; PA, prealbumin; $\mathrm{Cr}$, creatinine; D-D, D-dimer; WBC, leukocyte; Neu, neutrophils; Lym, lymphocyte; PLT, blood platelet; CD4, CD4 cells, CD4-positive T-lymphocytes.

most of the existed studies on the safety or risk of PPIs use were retrospective cohort studies or case-control studies, all of which lacked information on the pathogen or comorbidities of pneumonia. The mechanism of the safety or risk of PPIs has not been fully elucidated, and more highquality design studies are needed to confirm it. This study can not only preliminarily elucidate the effect of PPIs on the course of COVID-19 but also further provide the basis to verify whether the PPIs use increases the incidence of pneumonia.

To date, no effective drug treatment for COVID-19 has been found in large sample of high-quality clinical studies, ${ }^{19}$ except for remdesivir superior to placebo in shortening recovery times in adult patients hospitalized with COVID-19 and with evidence of lower respiratory tract infection. ${ }^{20}$ Therefore, other drugs were not included in the statistical analysis.

In terms of statistical methods, univariate analysis and multivariate analysis were performed in this study. Because univariate analysis showed that PPIs did not prolong or shorten the duration of SARS-CoV-2 clearance and hospital stay; all indicators were included in the multivariate analysis for progressive analysis, and the results of which also showed that PPIs did not extend or shorten the duration of SARS-CoV-2 clearance and hospital stay. We also applied the Kaplan-Meier statistics, Log Rank tests and the propensity score matching method, which showed PPIs did not increase or decrease the rate of the SARS-CoV-2 clearance and the discharge.

\section{Comparison with Related Literature}

So far, there have been more studies on the effect of PPIs on the occurrence of community-acquired pneumonia or hospital-acquired pneumonia, but these reports are inconsistent. However, research reports which investigate the effects of PPIs on COVID-19 are remarkably controversial.

Almario CV et al suggested that individuals using PPIs up to once daily (aOR $2.15 ; 95 \%$ CI, 1.90-2.44) or twice daily (aOR 3.67; 95\% CI, 2.93-4.60) had significantly increased odds for reporting a positive COVID-19 test when compared with those not taking PPIs. ${ }^{21}$ But, there were a lot of skepticism about this article by Almario CV. Aby ES et al pointed out flaws that the population on PPIs was younger than the overall group and the study found no significant differences between comorbid gastrointestinal conditions, diabetes, or human immunodeficiency virus among those positive for COVID-19, but pulmonary, cardiovascular, and renal diseases were not addressed. ${ }^{22}$ Hadi YB et al pointed out flaws that Almario CV et al collected information from participants on whether they received testing for the virus (not all participants were tested for COVID-19); and the number of participants tested for COVID-19 was not provided in the study, either in the whole cohort or in the individual groups. ${ }^{23}$ Hajifathalian $\mathrm{K}$ et al pointed out flaws that it was not clear from the 


\section{A}

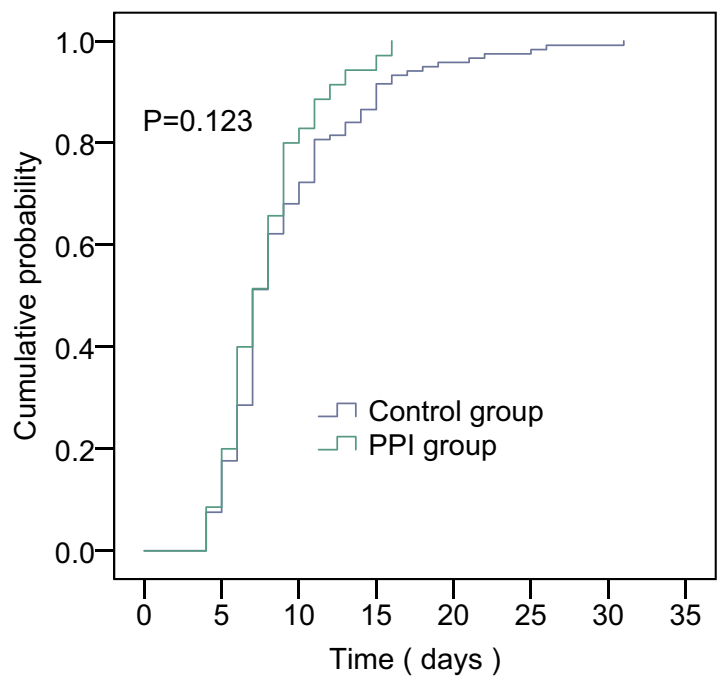

\section{No. at Risk}

$\begin{array}{lllllllll}\text { Control group } & 119 & 98 & 33 & 10 & 5 & 2 & 1 & 0 \\ \text { PPI group } & 35 & 28 & 6 & 1 & 0 & 0 & 0 & 0\end{array}$

B

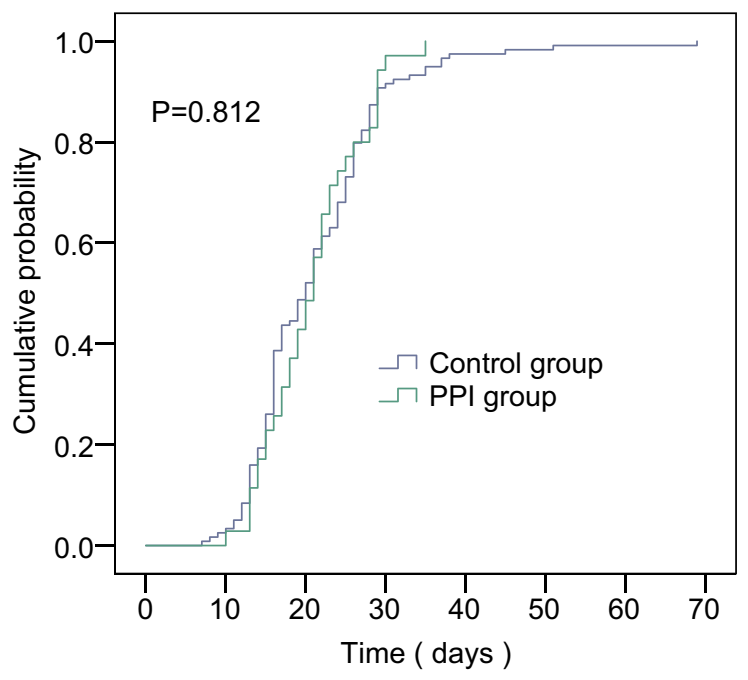

\section{No. at Risk}

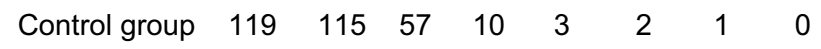

PPI group $\quad 35 \quad 34 \quad 18 \quad 1 \quad 000000$

Figure 2 Cumulative probability of SARS-CoV-2 clearance and discharge in COVID-19 patients between PPI group and control group. Kaplan-Meier curves of SARS-CoV-2 clearance $(\mathbf{A})$ and discharge (B) in the enrolled cases.

study whether the control group participants were tested and were COVID-19 negative or if they were a mix of tested and untested participants. ${ }^{24}$ Tarlow B et al pointed out flaws that the demographic data were unusual distribution; $74.5 \%$ aged $30-39$ years, $81 \%$ were married, $63.5 \%$ had a household annual income exceeding \$200,000 per year, $69 \%$ had a high school degree or less, unusually high $73.1 \%$ were every day smokers, $68.5 \%$ were from the
South; only $3.2 \%$ reported gastroesophageal reflux disease; $71.9 \%$ were reportedly taking PPI daily. ${ }^{25}$ Lee SW et al found that patients taking PPIs were not susceptible to SARS-CoV-2 infection. ${ }^{26}$ Due to so much flaws and controversies, further assessment of the findings by Almario et al should be performed.

Lee SW et al also found that patients taking PPIs were at increased risk for severe clinical outcomes of 
Table 2 Univariate and Multivariate Analyses of Predictive Factors for SARS-CoV-2 Clearance in COVID-I9 Patients

\begin{tabular}{|c|c|c|c|c|}
\hline \multirow[t]{2}{*}{ Variables } & \multicolumn{2}{|l|}{ Univariate Analysis } & \multicolumn{2}{|l|}{ Multivariate Analysis } \\
\hline & HR & $\mathbf{P}$ & HR & $\mathbf{P}$ \\
\hline Age: $\geq 60 /<60$ years & $0.837(0.599-1.169)$ & 0.297 & $0.984(0.645-\mid .502)$ & 0.941 \\
\hline Sex: male/female & $0.946(0.686-1.304)$ & 0.734 & $0.824(0.566-1.200)$ & 0.313 \\
\hline PPIs/not-PPIs & $1.309(0.893-1.918)$ & 0.168 & $1.575(0.993-2.499)$ & 0.054 \\
\hline HPT/not-HPT & $1.187(0.813-1.733)$ & 0.374 & $1.576(0.959-2.589)$ & 0.073 \\
\hline DM/not-DM & $0.909(0.503-1.642)$ & 0.751 & $1.136(0.513-2.517)$ & 0.754 \\
\hline CVD/not-CVD & $0.596(0.292-1.218)$ & 0.156 & $0.4 \mid 4(0.161-1.065)$ & 0.067 \\
\hline COPD/not-COPD & I.397(0.443-4.403) & 0.568 & $1.344(0.385-4.696)$ & 0.643 \\
\hline CLD/not-CLD & $2.037(0.750-5.532)$ & 0.163 & $2.293(0.642-8.193)$ & 0.201 \\
\hline CGD/not-CGD & $15.202(3.33 \mid-69.377)$ & $<0.001$ & $20.924(3.547-123.447)$ & $<0.001$ \\
\hline CKD/not-CKD & $0.944(0.233-3.821)$ & 0.935 & I.105(0.15I-8.087) & 0.922 \\
\hline MT/not-MT & I.I44(0.364-3.599) & 0.818 & $0.666(0.155-2.859)$ & 0.584 \\
\hline NPLI & $1.012(0.913-1.121)$ & 0.821 & $0.999(0.870-1.146)$ & 0.985 \\
\hline The onset times (days) & $0.993(0.952-1.035)$ & 0.735 & $0.993(0.948-1.040)$ & 0.764 \\
\hline CK: $\geq 198 /<198 \mathrm{U} / \mathrm{L}$ & $1.028(0.658-1.606)$ & 0.904 & $0.908(0.527-1.567)$ & 0.730 \\
\hline LDH: $\geq 252 /<152 \mathrm{U} / \mathrm{L}$ & $1.090(0.785-1.514)$ & 0.607 & $1.026(0.643-1.635)$ & 0.916 \\
\hline ALB: $<35 / \geq 35 \mathrm{~g} / \mathrm{L}$ & $1.259(0.662-2.395)$ & 0.483 & $0.985(0.408-2.377)$ & 0.973 \\
\hline $\mathrm{PA}:<280 / \geq 280 \mathrm{mg} / \mathrm{L}$ & $2.075(0.5 \mid 2-8.410)$ & 0.307 & $2.812(0.427-18.515)$ & 0.282 \\
\hline Cr: $\geq 104 /<104 \mu \mathrm{mol} / \mathrm{L}$ & $0.933(0.345-2.527)$ & 0.892 & $0.929(0.270-3.200)$ & 0.907 \\
\hline D-D: $\geq 0.5 /<0.5 \mathrm{mg} / \mathrm{L}$ & $1.053(0.743-1.493)$ & 0.771 & $1.006(0.60 I-1.685)$ & 0.981 \\
\hline \multicolumn{5}{|l|}{ WBC } \\
\hline$<4 / 4-10\left(\times 10^{9} / \mathrm{L}\right)$ & $1.425(0.450-4.517)$ & 0.547 & $1.414(0.332-6.015)$ & 0.639 \\
\hline$>10 / 4-10\left(\times 10^{9} / \mathrm{L}\right)$ & $1.25 \mathrm{I}(0.385-4.063)$ & 0.710 & $1.322(0.310-5.643)$ & 0.706 \\
\hline Neu: >70/ $\leq 70$ (\%) & $1.067(0.754-1.510)$ & 0.713 & $1.236(0.778-1.964)$ & 0.370 \\
\hline LYM: $<I . I / \geq I . I\left(\times 10^{9} / L\right)$ & $0.911(0.660-1.257)$ & 0.570 & $0.910(0.589-1.408)$ & 0.673 \\
\hline \multicolumn{5}{|l|}{ PLT } \\
\hline$<100 / 100-300\left(\times 10^{9} / \mathrm{L}\right)$ & $0.713(0.176-2.892)$ & 0.636 & $1.502(0.277-8.152)$ & 0.638 \\
\hline$>300 / 100-300\left(\times 10^{9} / \mathrm{L}\right)$ & $0.817(0.164-4.069)$ & 0.805 & $1.662(0.217-12.737)$ & 0.625 \\
\hline CD4: $<500 / \geq 500$ cells $/ \mu \mathrm{l}$ & $0.955(0.689-1.325)$ & 0.784 & $0.796(0.509-1.246)$ & 0.319 \\
\hline ALT: $>60 / \leq 60 \mathrm{U} / \mathrm{L}$ & $1.709(0.919-3.177)$ & 0.090 & $1.739(0.865-3.493)$ & 0.120 \\
\hline AST: $>60 / \leq 60 \mathrm{U} / \mathrm{L}$ & $1.717(0.834-3.533)$ & 0.142 & $1.387(0.466-4.128)$ & 0.557 \\
\hline
\end{tabular}

Abbreviations: PPIs, proton-pump inhibitors; HPT, hypertension; DM, diabetes mellitus; CVD, cardiovascular disease; COPD, chronic obstructive pulmonary disease; CLD, chronic liver disease; CGD, chronic gastric disease; CKD, chronic kidney disease; MT, malignant tumor; NPLI, number of pulmonary lobe inflammation; ALT, alanine aminotransferase; AST, aspartate aminotransferase; CK, creatine kinase; LDH, lactate dehydrogenase; ALB, albumin; PA, prealbumin; Cr, creatinine; D-D, D-dimer; WBC, leukocyte; Neu, neutrophils; Lym, lymphocyte; PLT, blood platelet; CD4, CD4 cells, CD4-positive T-lymphocytes.

COVID-19. ${ }^{26}$ But their study did not include other factors in the multivariate analysis, such as old age, chronic pulmonary disease and smoking, cardiovascular disease, chronic kidney disease, diabetes mellitus and obesity, malignancy and chronic $\mathrm{HIV}$ infection; ${ }^{27-33}$ which would also be risk factors for severe clinical outcomes of COVID-19. So, the use of PPIs could be a confounding factor for severe clinical outcomes of COVID-19. Luxenburger $\mathrm{H}$ et al found PPIs' treatment might be a negative predictive factor for development of secondary infections and consecutive ARDS in patients with COVID-19. ${ }^{34}$ But their results were only a comparison of baseline data, and no further analysis was performed to confirm whether the PPIs use was an independent factor for development of secondary infections and consecutive ARDS in patients with COVID-19. According to our study, the PPIs use had no relation with the duration of the SARS-CoV-2 clearance and the hospital stay, and some primary diseases and comorbidities prolonged the duration of the SARS-CoV-2 clearance and the hospital stay; which could not support the above findings by Lee SW and Luxenburger $\mathrm{H}$ et al. A meta-analysis showed that PPI usage was significantly associated with an increased risk of severe COVID-19 
Table 3 Univariate and Multivariate Analyses of Predictive Factors for Discharge in COVID-19 Patients

\begin{tabular}{|c|c|c|c|c|}
\hline \multirow[t]{2}{*}{ Variables } & \multicolumn{2}{|l|}{ Univariate Analysis } & \multicolumn{2}{|l|}{ Multivariate Analysis } \\
\hline & HR & $\mathbf{P}$ & HR & $\mathbf{P}$ \\
\hline Age: $\geq 60 /<60$ years & $0.759(0.543-1.063)$ & 0.108 & $0.652(0.410-1.039)$ & 0.072 \\
\hline Sex: male/female & $0.894(0.65 I-1.230)$ & 0.492 & $0.962(0.655-1.414)$ & 0.845 \\
\hline PPIs/not-PPIs & I.044(0.7|4-I.528) & 0.823 & $1.064(0.651-1.740)$ & 0.805 \\
\hline HPT/not-HPT & $1.250(0.854-1.829)$ & 0.250 & $1.820(1.073-3.085)$ & 0.026 \\
\hline DM/not-DM & $1.05 I(0.58 I-1.899)$ & 0.870 & $0.595(0.255-1.389)$ & 0.230 \\
\hline CVD/not-CVD & $0.917(0.429-1.962)$ & 0.823 & $\mathrm{I} .304(0.48 \mathrm{I}-3.538)$ & 0.602 \\
\hline COPD/not-COPD & $2.993(0.946-9.474)$ & 0.062 & $4.370(1.205-15.844)$ & 0.025 \\
\hline CLD/not-CLD & $6.183(2.180-17.534)$ & $<0.001$ & 9.011 (2.68I-30.290) & $<0.001$ \\
\hline CGD/not-CGD & $4.155(1.011-17.078)$ & 0.048 & $1.855(0.370-9.292)$ & 0.452 \\
\hline CKD/not-CKD & $1.404(0.346-5.699)$ & 0.635 & $1.911(0.344-10.621)$ & 0.459 \\
\hline MT/not-MT & $2.05 I(0.650-6.470)$ & 0.220 & $5.270(1.237-22.456)$ & 0.025 \\
\hline NPLI & $0.995(0.897-1.104)$ & 0.928 & $1.027(0.886-1.191)$ & 0.724 \\
\hline The onset times (days) & $1.000(0.96 I-1.04 I)$ & 0.993 & $1.017(0.972-1.064)$ & 0.463 \\
\hline SARS-CoV-2 clearance (days) & $0.911(0.876-0.948)$ & $<0.001$ & $0.907(0.869-0.947)$ & $<0.001$ \\
\hline CK: $\geq 198 /<198 \mathrm{U} / \mathrm{L}$ & $0.900(0.576-1.405)$ & 0.642 & $0.949(0.537-1.678)$ & 0.858 \\
\hline LDH: $\geq 252 /<152 \mathrm{U} / \mathrm{L}$ & $1.019(0.734-1.415)$ & 0.909 & $0.967(0.597-1.566)$ & 0.892 \\
\hline ALB: $<35 / \geq 35 \mathrm{~g} / \mathrm{L}$ & $0.979(0.5 \mid 4-1.865)$ & 0.949 & $0.630(0.290-1.369)$ & 0.243 \\
\hline $\mathrm{PA}:<280 / \geq 280 \mathrm{mg} / \mathrm{L})$ & $1.596(0.395-6.454)$ & 0.512 & $1.200(0.244-5.900)$ & 0.822 \\
\hline $\mathrm{Cr}: \geq 104 /<104 \mu \mathrm{mol} / \mathrm{L}$ & $1.017(0.376-2.753)$ & 0.974 & $0.885(0.276-2.836)$ & 0.837 \\
\hline D-D: $\geq 0.5 /<0.5 \mathrm{mg} / \mathrm{L}$ & $1.101(0.778-1.558)$ & 0.586 & $1.232(0.755-2.010)$ & 0.404 \\
\hline \multicolumn{5}{|l|}{ WBC } \\
\hline$<4 / 4-10\left(\times 10^{9} / L\right)$ & $1.07 \mid(0.339-3.38 I)$ & 0.907 & $0.574(0.163-2.021)$ & 0.387 \\
\hline$>10 / 4-10\left(\times 10^{9} / \mathrm{L}\right)$ & $0.869(0.267-2.824)$ & 0.815 & $0.540(0.152-1.917)$ & 0.341 \\
\hline Neu: >70/ $\leq 70$ (\%) & $1.091(0.773-1.540)$ & 0.620 & $1.392(0.872-2.223)$ & 0.166 \\
\hline LYM: $<1.1 / \geq 1.1 \quad\left(10^{9} / \mathrm{L}\right)$ & $0.822(0.596-1.134)$ & 0.233 & $0.75 I(0.480-1.173)$ & 0.208 \\
\hline \multicolumn{5}{|l|}{ PLT } \\
\hline$<100 / 100-300(\times 10, / L)$ & $1.138(0.280-4.619)$ & 0.856 & $0.927(0.162-5.297)$ & 0.932 \\
\hline$>300 / 100-300\left(\times 10^{9} / \mathrm{L}\right)$ & $1.228(0.246-6.117)$ & 0.802 & $0.866(0.123-6.097)$ & 0.886 \\
\hline CD4:<500/ $\geq 500 \mathrm{cell} / \mu \mathrm{l}$ & $0.885(0.640-1.224)$ & 0.459 & 1.055 (0.659-I.688) & 0.824 \\
\hline ALT: $>60 / \leq 60 \mathrm{U} / \mathrm{L}$ & $|.5 \mathrm{I}|(0.8 \mathrm{I} \mid-2.8 \mathrm{I} 5)$ & 0.193 & $1.311(0.643-2.674)$ & 0.456 \\
\hline AST: $>60 / \leq 60 \mathrm{U} / \mathrm{L}$ & $1.001(0.490-2.045)$ & 0.998 & $0.760(0.267-2.158)$ & 0.606 \\
\hline
\end{tabular}

Abbreviations: PPIs, proton-pump inhibitors; HPT, hypertension; DM, diabetes mellitus; CVD, cardiovascular disease; COPD, chronic obstructive pulmonary disease; CLD, chronic liver disease; CGD, chronic gastric disease; CKD, chronic kidney disease; MT, malignant tumor; NPLI, number of pulmonary lobe inflammation; ALT, alanine aminotransferase; AST, aspartate aminotransferase; CK, creatine kinase; LDH, lactate dehydrogenase; ALB, albumin; PA, prealbumin; Cr, creatinine; D-D, D-dimer; WBC, leukocyte; Neu, neutrophils; Lym, lymphocyte; PLT, blood platelet; CD4, CD4 cells, CD4-positive T-lymphocytes.

[RR 1.35 (95\% CI 1.11-1.63)] and mortality from COVID-19 infection [RR 1.72 (95\% CI 1.02-2.89)]; ${ }^{35}$ but, some confounding factors such as age and comorbid conditions were not matched, and there might be existence of literature selection and data coding bias, which could lead to different results.

However, there were several studies that supported the advantages of using proton-pump inhibitors in COVID-19 cases, based on basic research and inferences. ${ }^{17,18,38-43}$

Ray A et al suggested that the potential roles of PPIs based on specific cellular mechanisms and summarized all the relevant findings and information till date to get a wellbalanced and holistic view on the topic, and PPIs should strongly be considered as potential therapeutic options for COVID-19. ${ }^{36}$ Taştemur Ş et al suggested that PPIs could be used in prophylaxis too; however, in-vitro and in-vivo studies were required on PPIs that were thought to be beneficial for COVID-19 in acute and chronic processes with their anti-inflammatory, immunomodulatory and antifibrotic properties. ${ }^{37}$ But, in our clinical study, the PPIs use had no relation with the duration of the SARS-CoV-2 clearance. So, the antiviral mechanism of PPIs needs 
Table 4 Baseline Data of the Enrolled Cases After I:I PS Matching

\begin{tabular}{|c|c|c|c|}
\hline & $\begin{array}{l}\text { PPI Group } \\
(n=29)\end{array}$ & $\begin{array}{l}\text { Control Group } \\
(n=29)\end{array}$ & $\mathbf{P}$ \\
\hline Age (years) & $48(35-67)$ & $5 I(36-66)$ & 0.508 \\
\hline Sex,male (\%) & $16(55.2)$ & $16(55.2)$ & 1.000 \\
\hline HPT (\%) & $4(13.8)$ & $4(13.8)$ & 1.000 \\
\hline DM (\%) & $\mathrm{I}(3.4)$ & $\mathrm{I}(3.4)$ & 1.000 \\
\hline CVR (\%) & $2(6.9)$ & $2(6.9)$ & 1.000 \\
\hline COPD (\%) & $0(0)$ & $0(0)$ & 1.000 \\
\hline CLD (\%) & $\mathrm{I}(3.4)$ & $\mathrm{I}(3.4)$ & 1.000 \\
\hline CGD (\%) & $0(0)$ & $0(0)$ & 1.000 \\
\hline CKD(\%) & $0(0)$ & $0(0)$ & 1.000 \\
\hline MT (\%) & $0(0)$ & $0(0)$ & 1.000 \\
\hline NPLI & $4(2-5)$ & $4(2-5)$ & 0.923 \\
\hline $\begin{array}{l}\text { The onset times } \\
\text { (days) }\end{array}$ & $3(3-7)$ & $5(2-6.5)$ & 0.981 \\
\hline $\begin{array}{l}\text { SARS-CoV-2 } \\
\text { clearance (days) }\end{array}$ & $8(6-9)$ & $8(7-11)$ & 0.616 \\
\hline Hospital stay (days) & $21(16-27)$ & $19(16-24)$ & 0.478 \\
\hline ALT (U/L) & $20(15-35)$ & $20(15-34)$ & 0.957 \\
\hline AST (U/L) & $27(19-47)$ & $26(19-46)$ & 0.852 \\
\hline CK (U/L) & $102(5 I-181)$ & $109(51-189)$ & 0.785 \\
\hline LDH (U/L) & $244(186-326)$ & $238(185-324)$ & 0.715 \\
\hline ALB (g/L) & $\begin{array}{l}42.3 \\
(37.0-44.2)\end{array}$ & $42.6(36.8-44.4)$ & 0.969 \\
\hline PA (mg/L) & $153(92-192)$ & I55(89-20|) & 0.750 \\
\hline $\mathrm{Cr}(\mu \mathrm{mol} / \mathrm{L})$ & $\begin{array}{l}64.9 \\
(51.5-80.6)\end{array}$ & $64.3(51.2-80.2)$ & 0.797 \\
\hline D-D (mg/L) & $\begin{array}{l}0.34 \\
(0.27-0.6 I)\end{array}$ & $0.33(0.27-0.52)$ & 0.744 \\
\hline WBC $\left(\times 10^{9} / \mathrm{L}\right)$ & $4.3(3.8-6.0)$ & $4.4(3.9-5.9)$ & 0.864 \\
\hline Neu (\%) & $\begin{array}{l}62.8 \\
(52.5-73.3)\end{array}$ & $63.1(52.15-73.0)$ & 0.864 \\
\hline $\operatorname{Lym}\left(\times 10^{9} / \mathrm{L}\right)$ & $\begin{array}{l}1.07 \\
(0.70-1.40)\end{array}$ & $1.04(0.7-1.39)$ & 0.901 \\
\hline $\operatorname{PLT}\left(\times 10^{9} / \mathrm{L}\right)$ & $165(\mid 19-202)$ & $167(119-204)$ & 0.981 \\
\hline 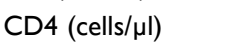 & $406(236-732)$ & $403(229-724)$ & 0.932 \\
\hline
\end{tabular}

Abbreviations: PPIs, proton-pump inhibitors; HPT, hypertension; DM, diabetes mellitus; CVD, cardiovascular disease; COPD, chronic obstructive pulmonary disease; CLD, chronic liver disease; CGD, chronic gastric disease; CKD, chronic kidney disease; MT, malignant tumor; NPLI, number of pulmonary lobe inflammation; ALT, alanine aminotransferase; AST, aspartate aminotransferase; $C K$, creatine kinase; LDH, lactate dehydrogenase; ALB, albumin; PA, prealbumin; $C r$, creatinine; D-D, D-dimer; WBC, leukocyte; Neu, neutrophils; Lym, lymphocyte; PLT, blood platelet; CD4, CD4 cells, CD4-positive T-lymphocytes.

further study, and more basic studies and clinical studies needed to confirm the effects of proton-pump inhibitors' use on various virus.

\section{Strengths of Study}

The data information included in this study was substantial, and the study date was dynamically monitored, including demographic characteristics and clinical information. A variety of statistical methods were applied to analyze whether the use of PPIs affected the course of COVID-19, effectively excluding the influence of confounding factors. Therefore, the results are relatively reliable. The study was conducted on COVID-19, which effectively excluded the confounding effects of pneumonia caused by other pathogens.

\section{Limitations of Study}

The baseline data of our study lacked the viral load of SARS-CoV-2; but lymphocytes and CD4 cells were included as the baseline reference, and they could make up for some of the deficiencies in our study; because it was proved that SARS-CoV-2 would affect the change of lymphocyte and CD4 cell counts. ${ }^{4-46}$ This study included only moderate COVID-19, and no severe and critical cases were included; therefore, the study did not fully represent the effect of PPIs on the course of severe or critical COVID-19. Since the PPIs were administered at regular dose in the short term, the study could not represent the effects of large doses or long-term use of PPIs on the course of COVID-19. The specimens of SARS-CoV-2 nucleic acid tested in our study were nasopharyngeal swab, while the specimens of SARS-CoV-2 nucleic acid tested in feces were not included in the statistics.

\section{Key Findings}

In this study, we found that the use of PPIs at regular dose in the short term in moderate COVID-19 did not prolong or shorten the duration of SARS-CoV-2 clearance or hospital stay. After preliminary screening, chronic gastropathy prolonged the duration of SARS-CoV-2 clearance; while hypertension, chronic bronchitis, chronic liver disease, and malignant tumors might prolong the duration of hospital stay in COVID-19 patients, and the SARS-CoV-2 clearance could shorten the duration of hospital stay in COVID-19 patients. Primary diseases and comorbidities were the main factors affecting the course of COVID-19, and the etiological treatment was important in COVID-19.

\section{Conclusion}

The use of proton-pump inhibitors does not prolong or shorten the duration of the SARS-CoV-2 clearance or hospital stay for patients with COVID-19. Therefore, the appropriate use of proton-pump inhibitors in the treatment or prevention of the related diseases will 
A

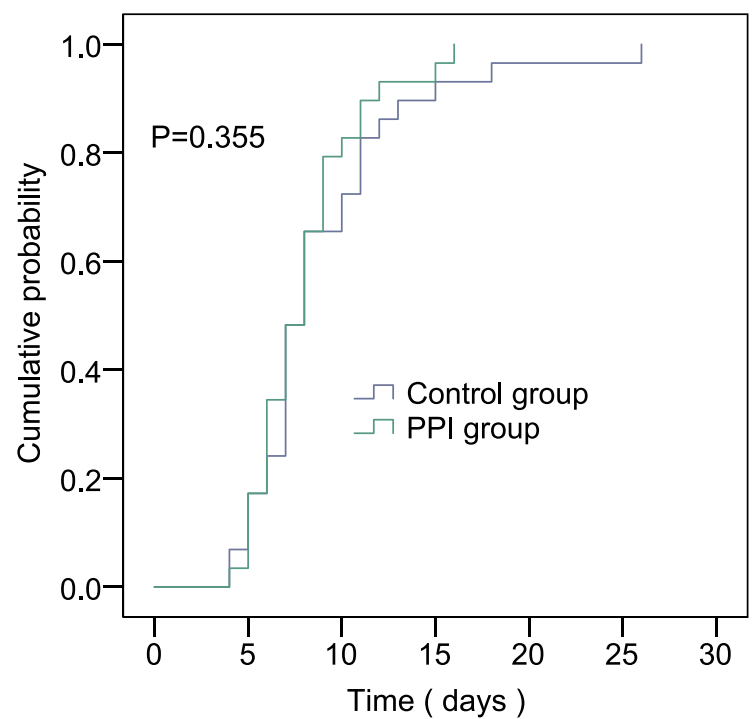

No. at Risk

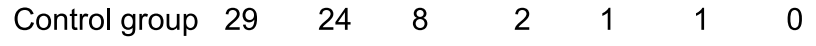

\begin{tabular}{|c|}
\hline PPI \\
\hline
\end{tabular}

B

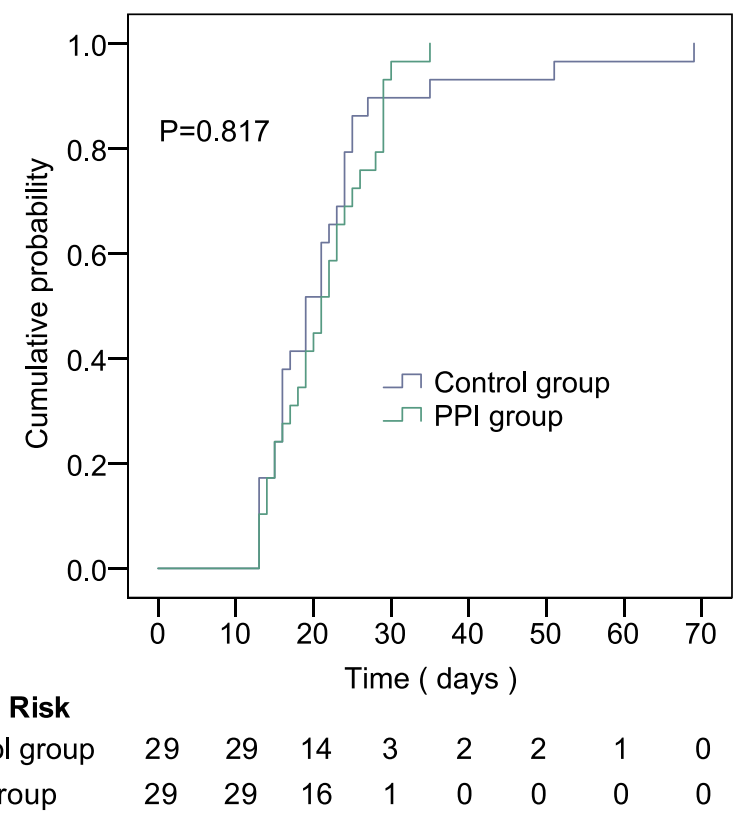

Figure 3 Cumulative probability of SARS-CoV-2 clearance and discharge in COVID-19 patients between PPI group and control group after I:I propensity score matching. Kaplan-Meier curves of SARS-CoV-2 clearance (A) and discharge (B) after I:I propensity score matching.

not affect the course of adults hospitalized with COVID-19.

\section{Data Sharing Statement}

The data included in the manuscript submitted to the journal are transparent. Individual participant data that underlie the results reported in this article, after deidentification (text, tables, and figures) will be shared. To make the data available, proposals should be directed to the corresponding author of this publication. To gain access, data requestors will need to sign a data access agreement. 


\section{Ethical Approval and Consent to Participate}

Informed consents of patients were obtained for diagnosis and treatment, and the study. Protocol was approved by the Shanghai Public Health Clinical Center Clinical Committee. All the data received Institutional Review Board (IRB) approval by the Ethics Committee. The IRB number was YJ-2020-S015-01.

\section{Acknowledgments}

This study was supported by the Shanghai Public Health Clinical Center for data access.

\section{Author Contributions}

All authors made a significant contribution to the work reported, whether that is in the conception, study design, execution, acquisition of data, analysis and interpretation, or in all these areas; took part in drafting, revising or critically reviewing the article; gave final approval of the version to be published; have agreed on the journal to which the article has been submitted; and agree to be accountable for all aspects of the work. Consent for publication: all authors have read and agreed to the published version of the manuscript. These authors contributed equally to this work and should be considered co-first authors: Xiao-Yu Zhang and Tao Li.

\section{Funding}

This research received no external funding.

\section{Disclosure}

The authors declare no conflicts of interest for this work.

\section{References}

1. CDC Weekly C, Team NCPERE. Vital surveillances: the epidemiological characteristics of an outbreak of 2019 novel coronavirus diseases (COVID-19) - China. China CDC Weekly. 2020;2(8):113-122. doi:10.46234/ccdew2020.032

2. World Health Organization. WHO Coronavirus Disease (COVID-19) Dashboard. Available from: https://COVID19.who.int/. Accessed January 27, 2021.

3. Huang C, Wang Y, Li X, et al. Clinical features of patients infected with 2019 novel coronavirus in Wuhan, China. Lancet. 2020;395 (10223):497-506. doi:10.1016/S0140-6736(20)30183-5

4. Guan WJ, Ni ZY, Hu Y, et al. Clinical characteristics of coronavirus disease 2019 in China. $N$ Engl J Med. 2020;382(18):1708-1720. doi:10.1056/NEJMoa2002032

5. Sarkar M, Hennessy S, Yang YX. Proton-pump inhibitor use and the risk for community-acquired pneumonia. Ann Intern Med. 2008;149(6):391-398. doi:10.7326/0003-4819-149-6-20080916000005
6. Laheij RJ, Sturkenboom MC, Hassing RJ, Dieleman J, Stricker BH, Jansen JB. Risk of community-acquired pneumonia and use of gastric acid-suppressive drugs. JAMA. 2004;292(16):1955-1960. doi:10.1001/jama.292.16.1955

7. Rodríguez LA, Ruigómez A, Wallander MA, Johansson S. Acidsuppressive drugs and community-acquired pneumonia. Epidemiology. 2009;20(6):800-806. doi:10.1097/ EDE.0b013e3181b5f27d

8. Eom CS, Jeon CY, Lim JW, Cho EG, Park SM, Lee KS. Use of acid-suppressive drugs and risk of pneumonia: a systematic review and meta-analysis. CMAJ. 2011;183(3):310-319. doi:10.1503/ cmaj.092129

9. Herzig SJ, Howell MD, Ngo LH, Marcantonio ER. Acid-suppressive medication use and the risk for hospital-acquired pneumonia. JAMA. 2009;301(20):2120-2128. doi:10.1001/jama.2009.722

10. Vaezi MF, Yang YX, Howden CW. Complications of proton pump inhibitor therapy. Gastroenterology. 2017;153(1):35-48. doi:10.1053/ j.gastro.2017.04.047

11. Hermos JA, Young MM, Fonda JR, Gagnon DR, Fiore LD, Lawler EV. Risk of community-acquired pneumonia in veteran patients to whom proton pump inhibitors were dispensed. Clin Infect Dis. 2012;54(1):33-42. doi:10.1093/cid/cir767

12. Giuliano C, Wilhelm SM, Kale-Pradhan PB. Are proton pump inhibitors associated with the development of community-acquired pneumonia? A meta-analysis. Expert Rev Clin Pharmacol. 2012;5(3):337-344. doi:10.1586/ecp. 12.20

13. Othman F, Crooks CJ, Card TR. Community acquired pneumonia incidence before and after proton pump inhibitor prescription: population based study. BMJ. 2016;355:i5813. doi:10.1136/bmj.i5813

14. Filion KB, Chateau D, Targownik LE, et al. Proton pump inhibitors and the risk of hospitalisation for community-acquired pneumonia: replicated cohort studies with meta-analysis. Gut. 2014;63(4):552558. doi:10.1136/gutjnl-2013-304738

15. Marker S, Barbateskovic M, Perner A, et al. Prophylactic use of acid suppressants in adult acutely ill hospitalised patients: a systematic review with meta-analysis and trial sequential analysis. Acta Anaesthesiol Scand. 2020;64(6):714-728. doi:10.1111/aas.13568

16. Wang $\mathrm{CH}$, Li CH, Hsieh R, et al. Proton pump inhibitors therapy and the risk of pneumonia: a systematic review and meta-analysis of randomized controlled trials and observational studies. Expert Opin Drug Saf. 2019;18(3):163-172. doi:10.1080/14740338. 2019.1577820

17. PubChem Database. Method of using $(\mathrm{H}+/ \mathrm{K}+)$ ATPase inhibitors as antiviral agents; 1996. Available from: https://pubchem.ncbi.nlm.nih. gov/patent/US5945425. Accessed July 29, 2020.

18. $\mathrm{Li} \mathrm{H}$, Meng $\mathrm{L}$, Liu $\mathrm{F}$, et al. $\mathrm{H}+/ \mathrm{K}+$-ATPase inhibitors: a patent review. Expert Opin Ther Pat. 2013;23(1):99-111. doi:10.1517/ 13543776.2013.741121

19. Sanders JM, Monogue ML, Jodlowski TZ, Cutrell JB. Pharmacologic treatments for coronavirus disease 2019 (COVID-19): a review. JAMA. 2020;323(18):1824-1836. doi:10.1001/jama.2020.6019

20. Beigel JH, Tomashek KM, Dodd LE. Remdesivir for the treatment of Covid-19 - preliminary report. $N$ Engl J Med. 2020;383(10):994. doi:10.1056/NEJMc2022236

21. Almario CV, Chey WD, Spiegel BMR. Increased risk of COVID-19 among users of proton pump inhibitors. Am $J$ Gastroenterol. 2020;115(10):1707-1715. doi:10.14309/ajg.0000000000000798

22. Aby ES, Rodin H, Debes JD. Proton pump inhibitors and mortality in individuals with COVID-19. Am J Gastroenterol. 2020;115(11):1918. doi:10.14309/ajg.0000000000000992

23. Hadi YB, Naqvi SF, Kupec JT. Risk of COVID-19 in patients taking proton pump inhibitors. Am J Gastroenterol. 2020;115 (11):1919-1920. doi:10.14309/ajg.0000000000000949

24. Hajifathalian K, Katz PO. Regarding "increased risk of COVID-19 in patients taking proton pump inhibitors". Am J Gastroenterol. 2020;115(11):1918-1919. doi:10.14309/ajg.0000000000000920 
25. Tarlow B, Gubatan J, Khan MA, Cholankeril G. Are proton pump inhibitors contributing to SARS-COV-2 infection? $\mathrm{Am}$ J Gastroenterol. 2020;115(11):1920-1921. doi:10.14309/ ajg.0000000000000933

26. Lee SW, Ha EK, Yeniova AÖ, et al. Severe clinical outcomes of COVID-19 associated with proton pump inhibitors: a nationwide cohort study with propensity score matching. Gut. 2021;70 (1):76-84. doi:10.1136/gutjnl-2020-322248

27. Grasselli G, Zangrillo A, Zanella A, et al. Baseline characteristics and outcomes of 1591 patients infected with SARS-CoV-2 admitted to ICUs of the Lombardy region, Italy. JAMA. 2020;323 (16):1574-1581. doi:10.1001/jama.2020.5394

28. Park SE, Park SE, Epidemiology PSE. Epidemiology, virology, and clinical features of severe acute respiratory syndrome -coronavirus-2 (SARS-CoV-2; coronavirus disease-19). Clin Exp Pediatr. 2020;63 (4):119-124. doi:10.3345/cep.2020.00493

29. Guan W-J, Liang W-H, Zhao Y, et al. Comorbidity and its impact on 1590 patients with COVID-19 in China: a nationwide analysis. Eur Respir J. 2020;55(5):2000547. doi:10.1183/13993003.00547-2020

30. Choi S-H, Kim HW, Kang J-M, et al. Epidemiology and clinical features of coronavirus disease 2019 in children. Clin Exp Pediatr. 2020;63(4):125-132. doi:10.3345/cep.2020.00535

31. Lighter J, Phillips M, Hochman S, et al. Obesity in patients younger than 60 years is a risk factor for COVID-19 hospital admission. Clin Infect Dis. 2020;71(15):896-897. doi:10.1093/cid/ciaa415

32. Dai M, Liu D, Liu M, et al. Patients with cancer appear more vulnerable to SARS-CoV-2: a multicenter study during the COVID-19 outbreak. Cancer Discov. 2020;10(6):783-791. doi:10.1158/2159-8290.CD-20-0422

33. Blanco JL, Ambrosioni J, Garcia F, et al. COVID-19 in patients with HIV: clinical case series. Lancet HIV. 2020;7(5):e314-6. doi:10.1016/ S2352-3018(20)30111-9

34. Luxenburger H, Sturm L, Biever P, et al. Treatment with proton pump inhibitors increases the risk of secondary infections and ARDS in hospitalized patients with COVID-19: coincidence or underestimated risk factor? J Intern Med. 2020;289(1):10.1111/joim.13121. doi:10.1111/joim.13121

35. Hariyanto TI, Prasetya IB, Kurniawan A. Proton pump inhibitor use is associated with increased risk of severity and mortality from coronavirus disease 2019 (COVID-19) infection. Dig Liver Dis. 2020;52(12):1410-1412. doi:10.1016/j.dld.2020.10.001
36. Ray A, Sharma S, Sadasivam B. The potential therapeutic role of proton pump inhibitors in COVID-19: hypotheses based on existing evidences. Drug Res (Stuttg). 2020;70(10):484-488. doi:10.1055/ a-1236-3041

37. Taştemur Ş, Ataseven H. Is it possible to use proton pump inhibitors in COVID-19 treatment and prophylaxis? Med Hypotheses. 2020;143:110018. doi:10.1016/j.mehy.2020.110018

38. Sasaki T, Nakayama K, Yasuda H, et al. A new strategy with proton pump inhibitors for the prevention of acute exacerbations in COPD. Ther Adv Respir Dis. 2011;5(2):91-103. doi:10.1177/ 1753465810392264

39. Becker JC, Grosser N, Waltke C, et al. Beyond gastric acid reduction: proton pump inhibitors induce heme oxygenase-1 in gastric and endothelial cells. Biochem Biophys Res Commun. 2006;345 (3):1014-1021. doi:10.1016/j.bbrc.2006.04.170

40. Vanfleteren LEGW, Spruit MA, Wouters EFM, Franssen FME. Management of chronic obstructive pulmonary disease beyond the lungs. Lancet Respir Med. 2016;4(11):911-924. doi:10.1016/S22132600(16)00097-7

41. Belouzard S, Millet JK, Licitra BN, et al. Mechanisms of coronavirus cell entry mediated by the viral spike protein. Viruses. 2012;4 (6):1011-1033. doi:10.3390/v4061011

42. Mazzon M, Marsh M. Targeting viral entry as a strategy for broadspectrum antivirals. F1000Res. 2019;8:F1000 Faculty Rev-1628. doi:10.12688/f1000research.19694.1

43. Marshansky V, Futai M. The V-type H+ -ATPase in vesicular trafficking: targeting,regulation and function. Curr Opin Cell Biol. 2008;20(4):415-426. doi:10.1016/j.ceb.2008.03.015

44. Liu Y, Yang Y, Zhang C, et al. Clinical and biochemical indexes from 2019-nCoV infected patients linked to viral loads and lung injury. Sci China Life Sci. 2020;63(3):364-374. doi:10.1007/s11427-020-1643-8

45. Wang D, Hu B, Hu C, et al. Clinical characteristics of 138 hospitalized patients with 2019 novel coronavirus-infected pneumonia in Wuhan, China. JAMA. 2020;323(11):1061-1069. doi:10.1001/ jama.2020.1585

46. Tan L, Wang Q, Zhang D, et al. Lymphopenia predicts disease severity of COVID-19: a descriptive and predictive study. Signal Transduct Target Ther. 2020;5(1):33. doi:10.1038/s41392-020-0148-4
Journal of Inflammation Research

\section{Publish your work in this journal}

The Journal of Inflammation Research is an international, peerreviewed open-access journal that welcomes laboratory and clinical findings on the molecular basis, cell biology and pharmacology of inflammation including original research, reviews, symposium reports, hypothesis formation and commentaries on: acute/chronic inflammation; mediators of inflammation; cellular processes; molecular mechanisms; pharmacology and novel anti-inflammatory drugs; clinical conditions involving inflammation. The manuscript management system is completely online and includes a very quick and fair peerreview system. Visit http://www.dovepress.com/testimonials.php to read real quotes from published authors. 